\title{
Effect of physical environment on survival of Helicobacter pylori
}

\author{
A P West, M R Millar, D S Tompkins
}

\begin{abstract}
Aims: To determine the effects of physical conditions on survival of Helicobacter pylori in aquatic environments. Survival for prolonged time intervals would implicate environmental water as a possible source of infection.

Methods: The effect of ionic strength, $\mathrm{pH}$, urea, protein and composition of incubation atmosphere on the survival of $H$ pylori NCTC 11637 and two clinical isolates (CI 82 and 92) was investigated.

Results: $H$ pylori strains survived for longer periods in physiological $(0 \cdot 15 \mathrm{M})$ saline than in $0.05 \mathrm{M}$ or $0.6 \mathrm{M}$ saline solution. Optimal pH range for survival was between pH 5.8 and 6.9. Addition of urea (final concentration $100 \mu \mathrm{M} / 1^{-1}$ and $5 \mathrm{mM}$ / $1^{-1}$ ) to neutral unbuffered $0 \cdot 15 M$ saline resulted in a reduction in survival; addition of bovine serum albumin $(1 \%)$ or gelatin $(1 \%)$ resulted in variable survival times compared with saline alone. Incubation in a microaerobic gas mixture prolonged survival compared with incubation in air.

Conclusion: $H$ pylori survival in water over a prolonged period is possible for a range of physical variables. The results indicate that $H$ pylori could survive in environmental water which may thus act as a potential reservoir of infection.
\end{abstract}

The mode of transmission of Helicobacter (Campylobacter) pylori infection in man is not known. There is some evidence to support person to person spread in those with prolonged close contact such as in families (Tytgat GNJ. Abstract, 13th International Congress of Gastroenterology, Rome, 1988), ${ }^{1}$ and a possible zoonosis in abattoir workers (D'Anastasio C, Vasra D, Holton J, et al. Abstract, 13th International Congress of Gastroenterology, Rome, 1988). Recently the municipal water supply was found to be an important potential source of infection in Peruvian children. ${ }^{2}$ Assessment of the ability of $H$ pylori to survive in water is therefore important. We have previously shown that $H$ pylori can survive in water and saline at $7^{\circ} \mathrm{C}$ for up to 16 days. ${ }^{3} \mathrm{We}$ report further investigations undertaken to assess the effect of changing physical conditions on $H$ pylori survival in water.

\section{Methods}

Helicobacter pylori NCTC 11637 and two clin- ical isolates (CI82 and CI92) from antral biopsy specimens were used. All strains were initially grown on a selective isolation medium for campylobacters (modified New York City medium $)^{4}$ for two days. All strains were stored in brain-heart-infusion broth (Oxoid) $37 \mathrm{~g} / \mathrm{l}$, yeast extract (Oxoid) $4 \mathrm{~g} / \mathrm{l}$, horse serum $10 \%$ $\mathrm{v} / \mathrm{v}$ and glycerol (BDH chemicals Ltd) $10 \%$ $\mathrm{v} / \mathrm{v}$, at $-70^{\circ} \mathrm{C}$. Before being used in this study $H$ pylori NCTC 11637 was subcultured five times. CI82 and CI92 were each subcultured once before use.

After microaerobic incubation (10\% carbon dioxide, $5 \%$ oxygen, $85 \%$ nitrogen) at $37^{\circ} \mathrm{C}$ for two days strains were harvested from whole plates of selective isolation medium into $10 \mathrm{ml}$ of sterile distilled water. Viable counts were determined by the inoculation of 10 -fold dilutions on to selective isolation media with microaerobic incubation. The remainder of the suspension was pipetted in $100 \mu$ l volumes into wells of sterile, U-well microlitre trays (Sterilin Ltd, Feltham, England) containing $100 \mu \mathrm{l}$ of double working strength saline or buffers. Each experiment was performed in triplicate. The suspensions and saline/buffer solutions were mixed thoroughly to give $200 \mu \mathrm{l}$ of final volume. Test suspension $(10 \mu \mathrm{l})$ from each well was pipetted on to selective isolation media for microaerobic incubation over two to five days.

After initial subculture of the test suspensions trays were placed in a Don Whitley stainless steel anaerobic gas jar which was evacuated and replaced with a gas mixture comprising carbon dioxide $10 \%$, oxygen $5 \%$, and nitrogen $85 \%$ or in an identical gas jar containing air. Blotting paper soaked in tap water was placed in jars to maintain high humidity and to minimise evaporation; trays were kept in loosely sealed plastic specimen bags. Both jars were left at room temperature which varied between $22-26^{\circ} \mathrm{C}$ (mean $23 \cdot 3^{\circ} \mathrm{C}$ ).

Additional $10 \mu \mathrm{l}$ samples were taken from triplicate wells every 24 hours and inoculated on to plates to determine bacterial growth. Colonies were tested for rapid urease, catalase, and Gram reactions to confirm identification of surviving organisms. This procedure was repeated until all suspensions became culture negative. $H$ pylori NCTC 11637 was investigated by this procedure on three separate occasions, with results shown as median survival values.

SURVIVAL

In salines of increasing ionic strength

All strains were tested for survival in sterile distilled water, $0.05 \mathrm{M}$ sodium chloride, 


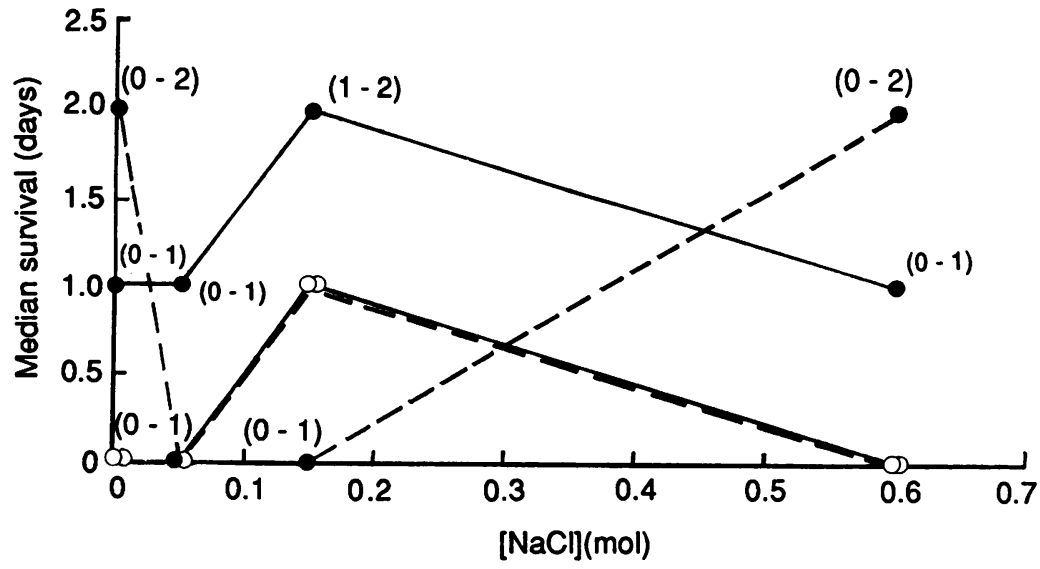

\begin{tabular}{|lrl|}
\hline Microaerobic & Aerobic \\
$\longrightarrow$ Hpylori & $-\infty-$ & Hpylori \\
NCTC 11637 & NCTC 11637 \\
- Hpylori & $-0-$ & Hpylori \\
C I 82 & C I 82 \\
\hline
\end{tabular}

Figure 1 Median days' survival of H pylori NCTC 11637 and C182 in saline at differing ionic strengths under aerobic and microaerobic conditions.

$0 \cdot 15 \mathrm{M}$ sodium chloride (physiological saline), and $0.6 \mathrm{M}$ sodium chloride (approximate ionic strength of seawater).

In buffers over a range of $\mathrm{pH}$ values

Survival of strains in $0.2 \mathrm{M}$ monobasic and $0.2 \mathrm{M}$ dibasic sodium phosphate buffer was investigated. Tests were carried out at $\mathrm{pH} 4 \cdot 5$, $5 \cdot 8,6 \cdot 9,8 \cdot 0$ and $9 \cdot 0 . H$ pylori NCTC 11637 was tested for survival in $0.1 \mathrm{M}$ citric acid- $0.2 \mathrm{M}$ sodium phosphate buffer at $\mathrm{pH} 2 \cdot 6,3 \cdot 1,4 \cdot 0,5 \cdot 0$, $6 \cdot 0,7 \cdot 0,70 \cdot 2 \mathrm{M}$ acetic acid-sodium acetate buffer $(\mathrm{pH} 3.0,3.2,3.6,4.0)^{5}$ and $0.2 \mathrm{M}$ TRIS (hydroxymethyl) aminomethanehydrochloric acid buffer ( $\mathrm{pH} 7 \cdot 2,7 \cdot 4,7 \cdot 6,7 \cdot 8$, $8 \cdot 0,8 \cdot 2,8 \cdot 4,8 \cdot 6,8 \cdot 8,9 \cdot 0){ }^{6}$

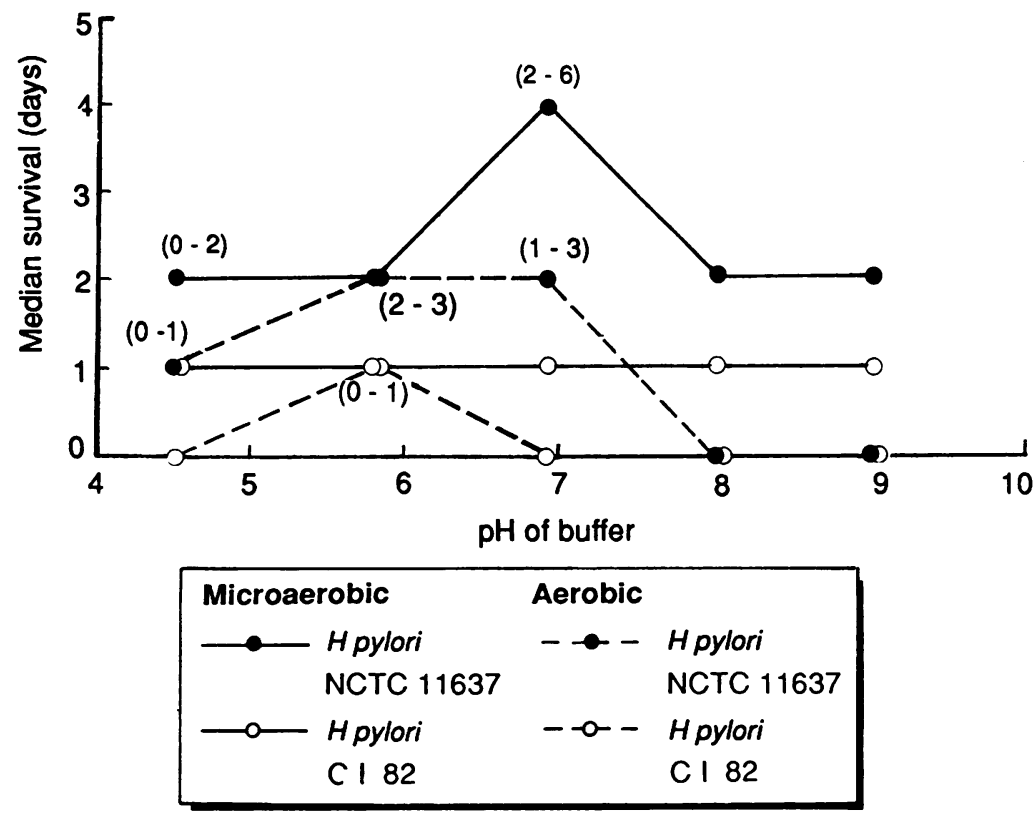

Figure 2 Median days' survival of H pylori NCTC 11637 and CI82 in sodium phosphate buffers of increasing $\mathrm{pH}$ under aerobic and microaerobic conditions.
In the presence of added urea and protein

Survival of strains in physiological saline with $100 \mu \mathrm{M} / 1$ or $5 \mathrm{mM} / 1$ was compared with survival in physiological saline alone.

Survival of strains in physiological saline with $1 \%$ bovine serum albumin (BSA) (Armour Pharmaceutical Co. Ltd; batch XR2870 fractionV from bovine plasma) or $1 \%$ gelatin (Sigma; swine skin, type I No. G-2500 300 Bloom) was compared with survival in physiological saline alone.

\section{Results}

The viable counts before microtitre tray inoculation ranged from $2.2 \times 10^{5}$ to $1.2 \times 10^{6}$ colony forming units (cfu) per ml among clinical isolates 82,92 , and $H$ pylori NCTC 11637 in distilled water suspensions. CI92 survived for less than one day under all conditions tested and was therefore considered to display zero survival. Variability in survival times between repeat experiments using the same strain was observed. Graphs (figs 1-4) therefore show the median of a range of survival times. Variation in survival times was either of unknown cause or due to contamination of inocula.

\section{SURVIVAL OF $H$ pylori}

In salines of increasing ionic strength

Optimal ionic strength conditions for survival of $H$ pylori were met at concentrations of $0.15 \mathrm{M}$ sodium chloride in microaerobic gas conditions where median days' survival ranged between one and two days for different strains or between experiments. In aerobic conditions survival was reduced at $0 \cdot 15 \mathrm{M}$ sodium chloride, but increased with NCTC 11637 in distilled water and $0.6 \mathrm{M}$ sodium chloride (fig 1).

\section{Over a range of $\mathrm{pH}$ values}

$H$ pylori strains survived in various buffers over a range of $\mathrm{pH}$ values ( $\mathrm{pH} \mathrm{4.5-9.0} \mathrm{in} \mathrm{micro-}$ aerobic atmospheres and $\mathrm{pH} 4 \cdot 5-8.0$ in air). Maximum survival in microaerobic gas mixtures occurred between $\mathrm{pH} 5 \cdot 8-6.9$ with the median varying from one to four days. In air survival was maximal between $\mathrm{pH} 5 \cdot 8-7 \cdot 0$ with median survival ranging between one and two days (figs 2 and 3). No survival was observed in acetate buffer either aerobically or microaerobically. No survival occurred in TRIS$\mathrm{HCl}$ buffer aerobically (fig 3).

\section{In saline and urea}

In microaerobic gas conditions there was no difference between survival of strains in saline and $0.1 \mathrm{mM}$ urea compared with saline alone. CI82 had a zero survival rate in saline with $5 \mathrm{mM} / \mathrm{L}^{-1}$ of urea. With NCTC 11637 there was no difference between median survival rate at $5 \mathrm{mM} / 1$ of urea compared with saline alone. In air neither of the strains survived in saline and urea (fig 4). Median survival ranged between one and two days.

In saline and protein

Slight or no differences in survival of $H$ pylori 

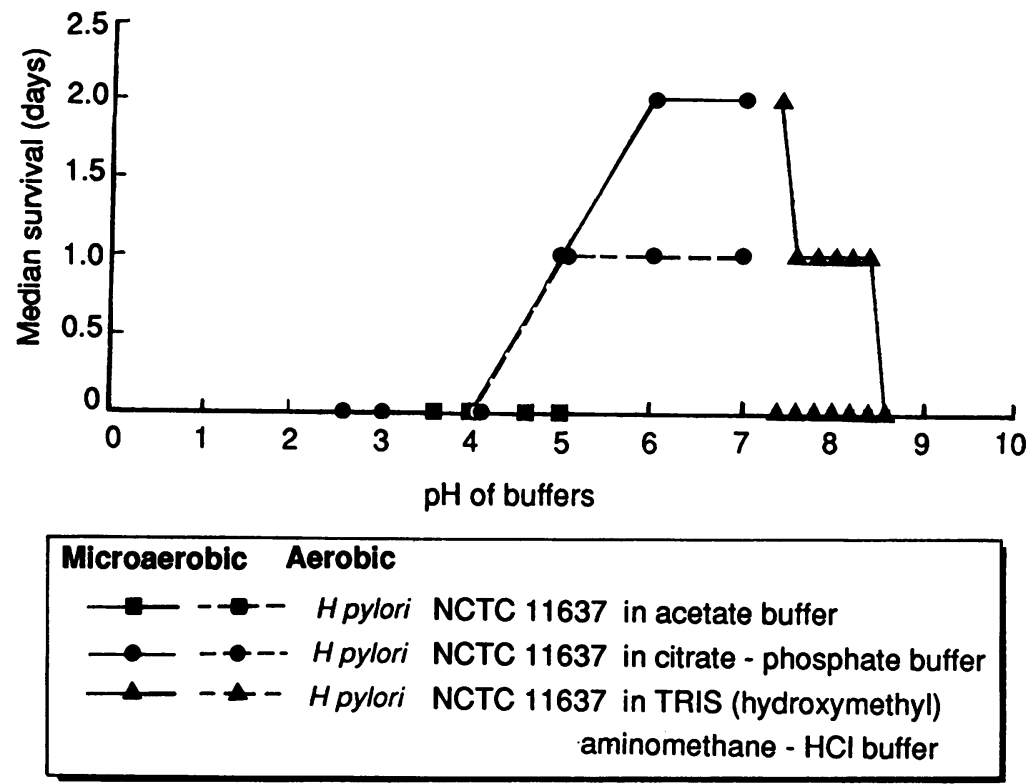

Figure 3 Median days' survival of H pylori NCTC 11637 and CI82 in different buffers at differing $p H$ ranges under aerobic and microaerobic conditions.

NCTC 11637 and CI82 were observed in saline with added protein microaerobically and aerobically stored compared with saline alone (table). $H$ pylori NCTC 11637 survived no better in saline and protein compared with saline in a microaerobic atmosphere. In air, the same strain displayed a lower survival in saline, although it was enhanced in saline with $1 \%$ BSA and gelatin. Median survival ranged between one and two days.

\section{Discussion}

The $\mathrm{pH}$ of environmental water is an important variable. $H$ pylori survives in $\mathrm{pH}$ buffered solutions over a wide $\mathrm{pH}$ range for short periods at room temperature. ${ }^{7}$ Growth of the

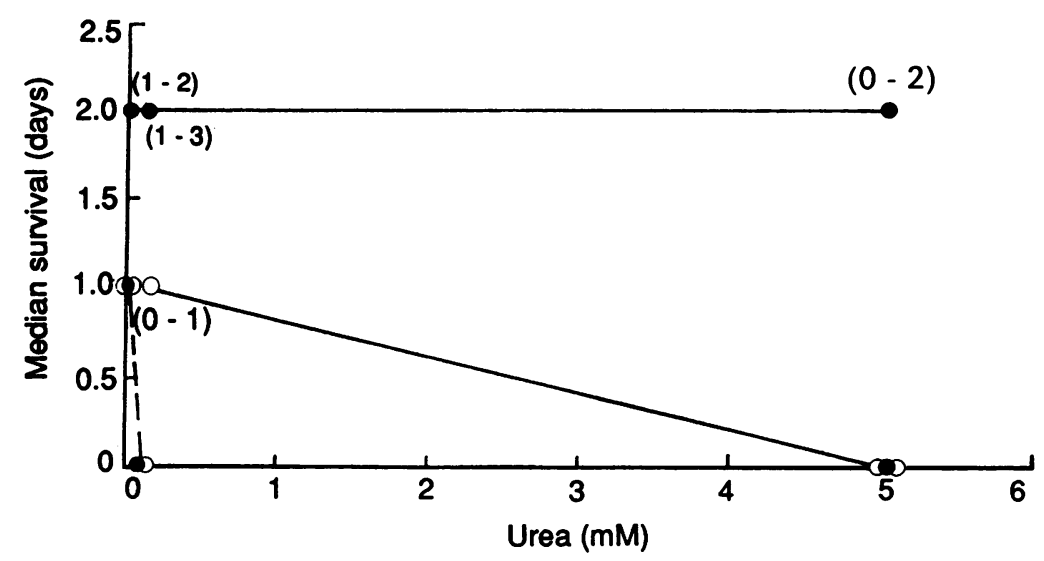

\begin{tabular}{|c|c|c|}
\hline Microaerobic & \multicolumn{2}{|l|}{ Aerobic } \\
\hline$\longrightarrow$ Hpylori & $-\rightarrow-$ & H pylori \\
\hline NCTC 11637 & & NCTC 11637 \\
\hline Oـ H pylori & $-\infty-$ & H pylori \\
\hline CI 82 & & C I 82 \\
\hline
\end{tabular}

Figure 4 Comparison of median survival time of $H$ pylori NCTC 11637 in physiological saline and physiological saline with $100 \mu \mathrm{M}$ and $5 \mathrm{mM}$ urea under aerobic and microaerobic conditions. organism has been achieved in supplemented broth cultures at similar $\mathrm{pH}$ values, ${ }^{10}$ and $H$ pylori is unusually tolerant to wide $\mathrm{pH}$ changes compared with many other pathogens. ${ }^{8}$ Our results show that survival of cells is possible for

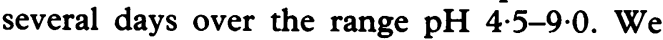
found that cell survival at $\mathrm{pH}$ values below $\mathrm{pH}$ 4.5 did not occur, which agrees with the findings of previous studies in which gross cell wall, flagellar, and cytoplasmic abnormalities were noted at $\mathrm{pH} 4.0$ or less. ${ }^{9}$ Although survival at either extreme of its viable $\mathrm{pH}$ range would be reduced, our investigations indicate that $H$ pylori could survive in natural aquatic environments where ranges of $\mathrm{pH} 3 \cdot 0-10.0$ may occur. ${ }^{10}$

Localised alkaline buffering of high acidity environments by urease hydrolysis of urea has been suggested as a mechanism for survival of $H$ pylori in low pH gastic juice. ${ }^{711}$ Whether this mechanism is a primary function of $H$ pylori urease, however, remains speculative because it is known that the organism exists under the stomach mucus layer near the mucosa, where conditions are buffered at or near $\mathrm{pH} 7 \cdot 0 .^{711}$ Our study shows that in neutral, unbuffered saline survival is significantly reduced by the addition of physiological concentrations of urea. This seems to be due to $H$ pylori urease activity, resulting in a rapid rise in $\mathrm{pH}$ to above $\mathrm{pH} 9 \cdot 0 .{ }^{12}$ Interestingly, we found that survival is comparatively higher in saline-urea suspensions in $10 \%$ carbon dioxide, where presumably cellular oxygen sensitivity is reduced and high $\mathrm{pH}$ moderated by increased concentrations of dissolved carbon dioxide, providing some acidbuffering capacity (Hudson MJ, Newell DG. Abstract, Gastroduodenal pathology and Campylobacter pylori workshop, Bordeaux, 1988). Rivers, streams, and lakes have a certain amount of buffering capacity in the form of dissolved gases and mineral salts ${ }^{13}$ which could help prevent rapid fluctuations in $\mathrm{pH}$ in the event of nitrogenous sewage pollution and the possible presence of $H$ pylori.

Water in lowland rivers or rivers polluted by sewage is more likely to be enriched by mineral salts ("eutrophic") compared with upland water containing few salts in solution ("oligotrophic").13 Salinity therefore varies in inland freshwater as well as estuarine water and seawater. Our observations indicate that physiological concentrations of salt and low oxygen tension provide optimal conditions for $H$ pylori survival. This agrees with the findings of previous studies which conclude that physiological saline provides a satisfactory transport medium for antral biopsy specimens prior to culture $\mathrm{e}^{14}$ and that microaerophilism is a general growth and adaptation characteristic. ${ }^{8}$ $H$ pylori does not grow on solid media with salt concentrations of $1.5 \% .^{12}$ We have found, however, that interstrain survival varies. Survival may occur in distilled water and $0.6 \mathrm{M}$ sodium chloride (approximate salinity of seawater) for appreciable time periods.

Considerable differences in survival times between $H$ pylori NCTC 11637 and clinical isolates CI82 and CI92 over a range of physical variables may have been due to a difference in 
Comparison of median survival time of $H$ pylori in physiological saline and physiological saline with $1 \% B S A$ and $1 \%$ gelatin under aerobic and microaerobic conditions.

\begin{tabular}{|c|c|c|c|c|c|c|}
\hline & \multicolumn{3}{|c|}{ Microaerobic conditions } & \multicolumn{3}{|c|}{ Aerobic conditions } \\
\hline & $0.5 \mathrm{M} \mathrm{Nacl}$ & $+1 \% B S A$ & $+1 \%$ Gelatin & $0.15 \mathrm{M} \mathrm{Nacl}$ & $+1 \% B S A$ & $+1 \%$ Gelatin \\
\hline $\begin{array}{l}\text { H pylori NCTC } 11637 \\
\text { H pylori clinical isolate } 82\end{array}$ & ${ }_{1}^{2(1-2)^{\star}}$ & $\begin{array}{l}2(0-2) \\
0\end{array}$ & $\begin{array}{l}2(0-2) \\
0\end{array}$ & $\begin{array}{l}1(0-1) \\
1(0-1)\end{array}$ & $\begin{array}{l}2(0-2) \\
1(0-1)\end{array}$ & $\begin{array}{l}2(1-2) \\
0\end{array}$ \\
\hline
\end{tabular}

* Numbers in parentheses refers to a range of survival days obtained from three or six experiments.

the frequency of subculture on solid media between these strains after storage. Repeated subculture could have led to laboratory adaptation and possible in vitro chromosomal mutation of the NCTC strain. Such genotypic variation has been found after an original $H$ pylori isolate was subcultured 10 times. $^{15}$ Another possible explanation for observed differences is the ability of $H$ pylori to produce non-culturable but viable coccoid forms under certain conditions. ${ }^{16} \mathrm{We}$ are currently investigating this possibility.

Bovine serum albumin in growth medium lacking fresh blood has been shown to permit growth of $H$ pylori due to adsorption to harmful peroxidated fatty acids. ${ }^{17} \mathrm{We}$ found that the addition of BSA and gelatin to physiological saline had little effect on $H$ pylori survival.

In conclusion, our results show that prolonged $H$ pylori survival in water, saline, and various buffers is possible at room temperature over a range of physical variables. They indicate that $H$ pylori could survive in environmental water.

We thank Dr Timothy J J Inglis and Mr Michael Sherratt for their support. We also thank Mrs Hilary Mobbs for secretarial assistance.

1 Berkowicz J, Lee A. Person-to-person transmission of Campylobacter pylori. Lancet 1987;ii:680-1.

2 Klein PD, Graham DY, Gaillour A, Opekun AR, O'Brien
Smith E. Water source as risk factor for Helicobacter pylori infection in Peruvian children. Lancet 1991; 337:1503-6.

3 West AP, Millar MR, Tompkins DS. Survival of Helicobacter pylori in water and saline. J Clin Pathol 1990;43:609.

4 Tompkins DS, Nehaul BBG, Smith CAF, Cook EM. Evaluation of the phadebact gonococcus test in the iden-
Evalus Evaluation of the phadebact gonococcus test in the iden-
tification of Neisseria gonorrhoea in a routine diagnostic tification of Neisseria gonorrhoea in a routin
laboratory. J Clin Pathol 1981;34:1106-9.

5 Dawson RMC, Elliot DC, Elliot WH, Jones KM. Data for biochemical research 2nd Edn Oxford: Oxford University Press, 1969;485-7.

6 Cruikshank R, Duguid JP, Marmion BP, Swain RHA. The practice of medical microbiology. Vol 2. Edinburgh Churchill Livingstone, 1975:88-9.

7 Tompkins DS, West AP. Campylobacter pylori, acid and bile. J Clin Pathol 1987;40:1387.

8 Morgan DR, Freedman R, Depew CE, Kraft WG. Growth of Campylobacter pylori in liquid media. J Clin Microbiol 1987;25:2123-5.

9 Dick DJ. Helicobacter (campylobacter) pylori-a new twist to an old disease. Ann Rev Microbiol 1990;44:249-69.

10 Kushner DJ. Microbial life in extreme environments. University of Ottawa, 1978:280-323.

11 Mooney C, Munster DJ, Bagshaw PF, Allardyce RA. Helicobacter pylori acid resistance. Lancet 1990;335:1232.

12 Rathbone BJ, West AP, Wyatt JI, Johnson AW, Tompkin DS, Heatley RV. Campylobacter pyloridis, urease and gastric ulcers. Lancet 1986;ii:400-1.

13 Mellanby K. Biology of pollution. 2nd ed. London: Edward Arnold, 1980:16-31.

14 Coudron PE, Kirby DF. Comparison of rapid urease tests, staining techniques and growth on different solid media for detection of Campylobacter pylori. J Clin Microbiol 1989;27:1527-30.

15 Oudbier JH, Langenberg W, Rauws EAJ, Bruin-Mosch C. Genotypic variation of Campylobacter pylori from gastric mucosa; J Clin Microbiol 1990;28:559-65.

16 Mai U, Geis G, Leying H, Ruhl G, Opferkuch W. Dimorphism of Campylobacter pylori. In: Megraud $F$ Lamouliatte $\mathrm{H}$, eds. Gastroduodenal pathology and Campylobacter pylori. Amsterdam: Elsevier Science Publishers BV. 29-33.

17 Hazell SL, Graham DY. Unsaturated fatty acids and viability of Helicobacter (Campylobacter) pylori. J Clin Microbiol 1990;28:1060-1. 